\title{
APLICACIÓN DEL TEST PROPORCIONALIDAD EN LA ARGUMENTACIÓN DE LAS RESOLUCIONES JUDICIALES EN \\ EL ÁMBITO DEL DERECHO CIVIL
}

\author{
Moisés Pablo Mariscal Rivera*
}

\section{INFORMACIÓN DEL ARTÍCULO}

Art. Recibido: 01/10/2019

Art. Aceptado: 04/11/2019

Art. Publicado: 30/12/2019

* Profesión: Abogado por la Universidad Nacional de San Agustín de Arequipa.

Grado Académico: Maestro en Derecho Procesal y Solución de Conflictos por la Universidad Peruana de Ciencias Aplicadas de Lima.

Laboral: Socio en el Estudio Jurídico Mariscal\&Galdos Abogados, Ciudad de Puno y Docente en la Facultad de Ciencias Jurídicas y Políticas de la Universidad Nacional del Altiplano de Puno. 
Journal homepage: http://revistas.unap.edu.pe/rd/ E-mail: revistaderecho@unap.edu.pe

\title{
RESUMEN:
}

El sistema jurídico no es permanente, completo, coherente y claro; por el contrario, debido a la globalización en la tecnología e información, así como a la profusa producción legislativa se ha tornado complejo y contradictorio, originándose antinomias internas y externas, siendo que ante ésta problemática el Juez Civil ha optado por realizar una aplicación específica de la ley.

El presente artículo de investigación se orienta a otorgar al Juez Civil la posibilidad de utilizar el Test de Proporcionalidad, para que la argumentación de su decisión no se base en la aplicación literal de la ley, sino que se realice desde la óptica de los Derechos Fundamentales y Principios Constitucionales involucrados en el caso concreto.

Palabras Claves: Proceso, Estado Constitucional, Derechos Fundamentales, Principios Constitucionales, Ponderación, Test de Proporcionalidad.

\begin{abstract}
:
The Judiciary System is just not permanent, complete, coherent and clear, on the contrary, by globalization in technology and information, as well as profuse legislative production, ii has tended to be complex and contradicting, affearing interior and exterior contradictions. So, with this kind of problem the civil Judge has choosen to do a special diligence or application.

The main aim of this investigation article is to give to the civil possibility to use the proportion test, so that, the matter of his decision it is not based in the original meaning application (diligence) of law, but it is being realized since the view of Fundamental Rights and Constitutional Principles involved in the certain case.
\end{abstract}

Keywords: Proceses, Constitucional State, Fundamental Rights, Constitutional Principles, Consideration, Proportionality Test. 


\section{1.- INTRODUCCIÓN}

En un mundo globalizado donde la tecnología y la información se desarrollan vertiginosamente, el Derecho como Ciencia que regula la conducta de las personas en sociedad juega un papel fundamental, sin embargo, ese rol se ve afectado al observar que el Sistema Jurídico ya no es permanente, completo, coherente y claro; por el contrario, debido a la profusa producción legislativa se ha tornado complejo y contradictorio, sumándose el hecho que el legislador no ha tenido la salvaguarda de sistematizar y concordar las normas legislativas, originándose antinomias internas y externas, así como también conflictos en la prevalencia entre derechos fundamentales, bienes y principios constitucionales.

A lo anotado se suma que desde hace unas décadas atrás en la doctrina jurídica se ha dejado de lado el sistema denominado como "Estado de Derecho", donde existía el predominio por la aplicación estricta de las normas, por el llamado "Neoconstitucionalismo o Estado Constitucional de Derecho", orientado a lograr la vigencia de los Derechos y Principios contenidos en la Constitución del Estado.

Ahora bien, conforme a la casuística que presentamos en el presente artículo de investigación se observará que el operador jurisdiccional en materia del derecho civil, ante la complejidad normativa, viene optando por realizar una aplicación formal de la Ley, tal cual sucedía en el Estado de Derecho; desconociendo de éste modo la vigencias y avances en materia de Derechos Fundamentales, Bienes y Principios Constitucionales, que deben prevalecer en el Sistema del Estado Constitucional de Derecho vigente en nuestros tiempos.

Precisamente, en virtud de la problemática descrita, el Juzgador en materia civil tiene una herramienta de argumentación jurídica para que su decisión no se base estrictamente en la aplicación específica de la ley, sino más bien que su fundamentación se construya tomando en cuenta los citados Derechos Fundamentales, Bienes y Principios recogidos en la Constitución, la misma que dentro de la técnica jurídica se identifica como el instrumento metodológico de argumentación constitucional del Test de Proporcionalidad, el mismo que permite evaluar si la intervención en un Derecho Fundamental o Principio Constitucional es justificado para hacer valer frente otro de la misma naturaleza, pero que para en un caso en concreto tiene un mayor valor o vigencia.

Cabe indicar que el Test de Proporcionalidad, no es un método que dependa de la subjetividad del operador de justicia, pues responde a una estructura (examen de idoneidad, necesidad y proporcionalidad en sentido estricto), que permite establecer en relación a un caso en concreto la prioridad de un derecho, bien o principio constitucional sobre otro de la misma naturaleza, para lograr la vigencia de los derechos que tengan más valor ante la problemática que da origen a su invocación y aplicación.

Para materializar la utilidad del test de proporcionalidad, se construirá una base teórica para luego proceder al análisis de las citadas resoluciones judiciales emitidas por diferentes instancias judiciales de nuestro país, lo cual permitirá visualizar que los jueces especializados en materia civil, recurren al mandato específico de la ley para sostener sus decisiones, incluso, se podrá observar que se realiza una invocación lírica de los principios de origen constitucional, desconociendo su naturaleza jurídica y contenido; todo lo cual 
Journal homepage: http://revistas.unap.edu.pe/rd/ E-mail: revistaderecho@unap.edu.pe

va en perjuicio de los ciudadanos que por múltiples factores se ven en la necesidad de recurrir al sistema judicial para resolver un conflicto o incertidumbre legal y donde esperan una decisión razonable del juzgador, con respeto a sus derechos fundamentales y cumpliendo un mínimo estándar de calidad en la motivación.

\section{2.- LOS LÍMITES AL CONTENIDO DE LOS DERECHOS FUNDAMENTALES.}

En la doctrina no existe una posición de consenso respecto a cuales son los límites que abarcan los derechos fundamentales. De hecho, existen posiciones encontradas, pues hay quienes conciben a tales derechos como realidades con un contenido limitado desde la propia Constitución, siendo que esos límites deben ser descubiertos por el intérprete mediante la interpretación teleológica; y, por otro lado, hay quienes sostienen que los derechos fundamentales son concebidos como normas de principio o mandatos de optimización con un contenido normativo que se expande en la mayor medida posible y cuyo cumplimiento debe efectuarse en un grado óptimo. Precisamente, para poder establecer el alcance de estas posiciones encontradas, conviene desarrollar con mayor amplitud los alcances de sus teorías, así tenemos que:

\section{1.- La teoría de los límites internos o del contenido propio de los derechos} fundamentales; Sostiene que a partir del surgimiento del Neoconstitucionalismo, se adoptó en las Constituciones modernas la postura referente a que los Derechos Fundamentales constituyen una manifestación de un ordenamiento justo que respeta la dignidad del ser humano, por el sólo hecho de serlo, razón por la que no se puede admitir que sean restringidos a efecto de preservar otros bienes, o que conductas que constituyen el legítimo ejercicio de un derecho carezcan de protección constitucional.

Por ello, para la teoría de los límites internos, todo derecho fundamental tendría sus propios límites o contornos, que vendrían determinados desde la propia Constitución y que definirían su contenido constitucionalmente protegido, sin necesidad de acudir a ningún elemento externo de ponderación o delimitación, como por ejemplo, el llamado Test de Proporcionalidad.

En ese orden, TOMAS DE DOMINGO PÉREZ", sostiene que: "Con independencia de otras consideraciones, la construcción de Robert Alexy y, en general, la apuesta por el principio de proporcionalidad altera profundamente el sentido original de la concepción de la justicia que introduce el Neoconstitucionalismo. Como se ba señalado, el Neoconstitucionalismo sostiene que los derechos fundamentales constituyen el núcleo de lo justo y, en consecuencia, el criterio básico de justicia de la comunidad politica. Semejante teoría de la justicia no puede admitir sin resultar incoherente que los derechos fundamentales sean restringidos -más allá de las restricciones contempladas en el propio texto constitucional-para preservar bienes colectivos, o que conductas que constituyen el legitimo ejercicio de un derecho fundamental -definitivamente, no prima facie- carezcan de protección institucional. La apuesta por el principio de proporcionalidad supone renunciar a una teoría material de la justicia en favor de una

\footnotetext{
${ }^{49}$ De Domingo Pérez 2008: 17-32.
} 
Journal homepage: http://revistas.unap.edu.pe/rd/ E-mail: revistaderecho@unap.edu.pe

teoría procedimental de la justicia, pues en eso se traduce la apuesta por un procedimiento argumentativo disciplinado por reglas formales como el principio de proporcionalidad".

La postura asumida por el citado autor es utilizada por quienes defienden esta teoría para argumentar que las situaciones que aparentemente se presentan como colisiones entre derechos fundamentales u otros bienes jurídicos constitucionalmente legítimos, y que exigirían la limitación de alguno de ellos, es en la realidad problemas de "delimitación" conceptual de sus respectivos contenidos que no existen ni generan conflictos entre pretensiones, así por ejemplo: en el supuesto de que unos padres se nieguen a aceptar una transfusión de sangre que es necesaria para salvar la vida de su hijo, por tenerlo prohibido por la religión que profesan, no constituye de modo alguna una contraposición entre los derechos a la vida que tiene el citado menor con el derecho a la libertad de credo que tienen sus padres, porque la transfusión es una exigencia derivada del derecho a la vida, consecuentemente, no podría verse limitado ante la manifestación válida de la libertad religiosa de sus padres, es decir, en mérito a la importancia y contenido al derecho a la vida no cabría ninguna discusión con referencia a la libertad de credo.

Entonces, para la citada teoría es imposible que los derechos fundamentales puedan colisionarse entre sí, afirmando que cualquier conflicto entre derechos solo constituye una apariencia, porque si se observa con cuidado cada derecho fundamental tiene su propio límite y es congruente con los otros derechos reconocidos en los textos constitucionales, es decir, no hay espacio para sostener incongruencias, menos aún, incompatibilidades entre unos y otros de los derechos en juego ante un caso concreto.

En base a la lógica descrita, autores nacionales como LUIS CASTILLO CÓRDOVA ${ }^{50}$, asume la postura de que: "Los derechos fundamentales son reconocidos en conjunto y en conjunto ban de ser determinados y concretados en su contenido constitucional, y en conjunto también ban de ejercitarse (...). Consecuentemente, el intérprete a la hora de determinar o concretar una disposición constitucional no podrá limitarse a su solo texto sino que deberá orientarse según la causa y fin que está vinculada al derecho fundamental que recoge. Es lo que normalmente suele conocerse con el nombre de interpretación teleológica”.

En buena cuenta para el autor, es insostenible la existencia de conflictos entre derechos fundamentales, porque en mérito a su interpretación teleológica se logra concretar y determinar su contenido de forma armónica, esto es, sin conflictos respecto a su contenido por medio que dé lugar al sacrificio, restricción o lesión de un derecho fundamental en consideración con los demás derechos y bienes jurídicos constitucionales igualmente vigentes y vinculantes, desterrando así la aplicación del llamado Test de Proporcionalidad.

\section{2.- La teoría de los límites externos al contenido de los derechos} fundamentales. Dicha teoría no niega la posibilidad de que el propio texto constitucional establezca ciertas pautas para la determinación del contenido a los derechos fundamentales, incluso, abona por la interpretación teleológica, sin embargo, sostiene que existen supuestos en los cuáles pese a la utilización de este mecanismo interpretativo no

\footnotetext{
${ }^{50}$ Castillo Córdova 2008: 37-52.
} 
Journal homepage: http://revistas.unap.edu.pe/rd/ E-mail: revistaderecho@unap.edu.pe

se logra salvar la contraposiciones en los alcances de cada derecho, más aún, si se tiene presente que los textos constitucionales por su estructura no siempre contiene una regulación de los derechos de forma sistemática y congruente, pues se limitan a establecer una declaración de derechos; razón por la que se admite la posibilidad de que su contenido se vea limitado al concurrir con otros derechos fundamentales ante un supuesto de hecho concreto, surgiendo la necesidad de utilizar un instrumento metodológico para poder identificar la limitación de un derecho sobre otro para efectos de alcanzar fines constitucionalmente legítimos; precisamente, ese instrumento es el llamado Test de Proporcionalidad.

En ese sentido, la investigadora colombiana MAGDALENA CORREA HENAO ${ }^{51}$, refiere que: "La teoría de los límites externos a diferencia de la teoría de los límites internos, considera que el contenido del derecho fundamental y sus límites pueden ser concebidos como categorías distintas y separadas entre si de manera que estos últimos aparecerían como restricciones al primero. De ello, se desprende que la noción de limites sea externa o distinta del derecho y provenga de la necesidad, si del caso se trata de hacer compatible el derecho con otros derechos y con los demás bienes constitucionalmente protegidos (...) En virtud a lo anotado es que surge la concepción de los derechos fundamentales como principios, es decir, como mandatos de optimización, cuyo contenido debe realizarse en la mayor medida posible de acuerdo a las posibilidades fácticas y jurídicas. Desde esta óptica, los derechos fundamentales son en principio y por su propia naturaleza, realidades jurídicas que tienden a expandirse de forma ilimitada y que necesitarian de restricciones externas solo por la necesidad de coexistir con otros derechos fundamentales. En ese sentido, a diferencia de la teoría de los limites internos y del contenido propio de los derechos fundamentales, la teoría de los limites externos admite la posibilidad de conflicto, y resulta compatible con la aplicación del principio de proporcionalidad como mecanismo para efectuar una ponderación de los principios concurrentes, asi como para evaluar la validez de las restricciones o limitaciones impuestas desde fuera, a su contenido".

De lo trascrito podemos advertir que para los defensores de la teoría de los límites externos al contenido de los derechos fundamentales, si bien reconocen como verdad que la regla general en el Estado Constitucional es la vigencia de los Derechos Fundamentales, también es cierto que estos derechos, pueden ser restringidos a partir del acto fundacional de la sociedad civil, con el objetivo de lograr la armonización en el ejercicio de esos derechos por parte de sus titulares, así por ejemplo, URSULA INDACOCHEA PREVOST" ${ }^{52}$, sostiene que: "La concurrencia de un derecho fundamental con otros bienes jurídicos puede justificar que se límite válidamente su contenido, siempre que estos últimos resulten legítimos desde el punto de vista constitucional, y que la medida limitadora supere las exigencias del principio de proporcionalidad, lo cual contribuirá a redefinir dicho contenido, en cada caso concreto. Por el contrario, si la limitación no superase tales parámetros, estariamos frente ante una intervención inválida en el contenido del derecho fundamental, que sería por lo tanto, inconstitucional".

Entonces, para un sector de la doctrina, la aplicación del Test de Proporcionalidad permite implementar ese análisis sobre los límites de los derechos fundamentales sometidos a conflicto, tanto más, si tenemos presente que en el Estado Constitucional no puede hacerse valer cualquier restricción a los Derechos Fundamentales, sino sólo

${ }^{51}$ Correa Henao 2003:69.

52 Indacochea Prevost 2008: 27-38. 
Journal homepage: http://revistas.unap.edu.pe/rd/ E-mail: revistaderecho@unap.edu.pe

aquellas restricciones que sean idóneas para contribuir a la obtención de cierto fin legítimo; necesarias, es decir, las más benignas entre todos los medios alternativos que gocen de por lo menos la misma idoneidad para conseguir la finalidad deseada; y proporcionales en sentido estricto, es decir, aquéllas que logren un equilibrio entre los beneficios que su implementación representa y los perjuicios que ella produce.

En mérito a lo desarrollado es que el Test de Proporcionalidad juega un rol importante en la interpretación constitucional para el control de constitucionalidad de las leyes, así por ejemplo; contribuye a determinar aquel contenido "definitivo" del derecho fundamental intervenido o limitado que va resultar vinculante para el legislador; y, además, permite estructurar la justificación externa de la premisa mayor a ser utilizada en el proceso de análisis constitucional en el que se verifica si el contenido de una determinada ley objeto de control es compatible o incompatible con el contenido de un derecho constitucional.

Estando a los fundamentos descritos, en el presente trabajo de investigación se adopta la segunda teoría, es decir, la referente a los límites externos al contenido de los derechos fundamentales, porque en muchos casos por más interpretación teleológica que se realice existen aquellos donde colisionan los derechos fundamentales, es más, así lo ha advertido el Tribunal Constitucional en su Jurisprudencia, teniendo que recurrir al Test de Proporcionalidad, como un criterio metodológico para determinar los límites que los propios derechos fundamentales le imponen a la actividad limitadora, por ello es que en el presente trabajo se propone que este método pueda ser aplicado por los Jueces especializados en materias civiles y en mérito a la facultad de control difuso que les reconoce la Constitución y su Ley Orgánica, pues mediante su aplicación se logrará establecer la plena vigencia de los derechos fundamentales que tienen los ciudadanos; $y$, lo más importante, se logrará otorgar solución al conflicto de intereses o incertidumbre legal con un criterio de proporcionalidad y con respeto a la vigencia de los derechos constitucionales.

\section{3.- EL TEST DE PROPORCIONALIDAD.}

\section{1.- Antecedentes y Definición:}

Mediante el surgimiento y posterior consolidación del Estado Constitucional de Derecho, las principales Constituciones Europeas y Latinoamericanas han establecido una teoría material de justicia basada en el reconocimiento a la dignidad humana y el respeto a los derechos fundamentales, como las bases en las que se fundamenta una ordenación justa de la sociedad y la comunidad política.

En ese orden, los Derechos Fundamentales por su propia naturaleza, son aquellos que en el ámbito de la personalidad y/o actuación humana son reconocidos como dignos de protección a través de la Constitución del Estado, siendo que al ser constitucionalizados se convierten en un criterio básico de justicia, por lo que todas aquellas acciones -tanto de particulares como de poderes públicos- que los lesionan son calificadas de injustas, sin embargo, también es cierto que estos derechos, pueden ser restringidos a partir del acto fundacional de la sociedad civil, con el objetivo de lograr la armonización en el ejercicio de esos derechos por parte de sus titulares, surgiendo de éste modo el Test de Proporcionalidad como esa pauta metodológica para el control constitucional de todo acto que intervenga los derechos fundamentales. 
Journal homepage: http://revistas.unap.edu.pe/rd/ E-mail: revistaderecho@unap.edu.pe

En esa lógica, fue el alemán ROBERT ALEXY ${ }^{53}$, quien partiendo de un análisis de las relaciones entre derechos individuales y bienes colectivos, establece que una cosa es el derecho individual y otra el bien colectivo consistente en los efectos beneficiosos que para la colectividad pueda tener una organización de vida política y jurídica que facilite el libre desarrollo de la personalidad de todas las personas. Sin embargo, observa que no se trata de que el pleno ejercicio de los derechos fundamentales permita alcanzar una situación valiosa desde el punto de vista colectivo. La posibilidad de ejercer libremente los derechos fundamentales no es un bien por sus consecuencias, sino que es algo valioso por sí mismo por cuanto así lo exige la dignidad humana, empero, existen circunstancias en que existe una colisión entre los derechos en mención, surgiendo la necesidad de restringirlos para preservar no solo otros derechos fundamentales, sino también bienes colectivos, razonamiento que lo lleva a crear el llamado Test de Proporcionalidad, como un método que permita establecer cuando un derecho fundamental debe ser intervenido para preservar otro de mayor valor ante un supuesto de hecho concreto.

A mayor detalle, ROBERT ALEXY, sostiene que las normas constitucionales que reconocen los derechos fundamentales y/o bienes colectivos presentan la estructura de principios a los cuáles los define como mandatos de optimización, esto es, normas que requieren del máximo grado de realización en función de las posibilidades fácticas y jurídicas que conceptualizan su ejercicio, siendo que cuando entran en colisión (lo cual es altamente probable por la gran cantidad de principios con diverso contenido y amplio radio de acción que recoge la Constitución) debe aplicarse el Test de Proporcionalidad, para establecer cual mandato de optimización debe prevalecer ante el supuesto de hecho que da origen a esa colisión.

Ampliando la pauta metodológica creada por ROBERT ALEXY, el español CARLOS BERNAL PULIDO ${ }^{54}$, refiere que se ha desarrollado dos tesis para explicar el estatus jurídico del Test de Proporcionalidad, así por ejemplo, indica que para la primera tesis, la proporcionalidad sería un principio general del derecho que expresa un criterio de interpretación de los derechos fundamentales; en contraposición, para la segunda tesis, el Test representaría una metodología al "limite de los límites" derechos fundamentales.

La primera tesis ha sido objetada por los estudioso del derecho, en el sentido de que si se considera al Test de Proporcionalidad como un principio general del derecho habría que vincularlo a la interpretación jurídica, lo cual no ayudaría a identificarlo como una figura dogmática autónoma, dada la dificultad y falta de consenso que existe en la doctrina sobre las características específicas de los citados principios. En contraposición, por la segunda tesis, se identifica que el Test de Proporcionalidad descansa en la idea de que las restricciones o limitaciones impuestas a los derechos fundamentales debe estar sujeto a límites, operando como una pauta metodológica para hacer efectivos los mandatos que se deriva de los derechos constitucionales.

Precisamente, en mérito al contenido de la segunda tesis es que el Test de Proporcionalidad, se define como instrumento metodológico de argumentación para

\footnotetext{
53 Alexy 1993: 13-64.

${ }^{54}$ Bernal Pulido 2005: 81-85.
} 
Journal homepage: http://revistas.unap.edu.pe/rd/ E-mail: revistaderecho@unap.edu.pe

solucionar una colisión de principios mediante el establecimiento de una relación de precedencia condicionada a efecto de determinar en cada caso concreto, si hubo una excesiva afectación de los derechos fundamentales en juego, por lo tanto, se entiende que desempeña el rol de una metodología antes que un principio en sí mismo.

En consecuencia, el Test de Proporcionalidad es pauta metodológica y como tal tiene un contenido que se conforma de tres presupuestos a los cuales se identifica como presupuestos o juicios, siendo el primero de ellos el denominado como adecuación o idoneidad, por el cual toda afectación a un derecho fundamental debe perseguir una finalidad constitucionalmente válida y debe ser apta para conseguir su vigencia. El segundo presupuesto obedece al llamado juicio de necesidad, por el cual se debe analizar si la medida restrictiva al derecho fundamental intervenido es menos violatoria para alcanzar la finalidad constitucionalmente perseguida; $y$, por el tercer presupuesto se tiene a la proporcionalidad en sentido estricto, por el cual la satisfacción de los derechos o bienes constitucionales que se busca proteger u optimizar con la medida interventora debe ser mayor que la afectación que genera sobre el contenido de los derechos restringidos.

\section{2.- Presupuestos del Test de Proporcionalidad.}

3.2.1.- Presupuesto de Idoneidad: Por este presupuesto se entiende que toda intervención en los derechos fundamentales debe ser idóneo para contribuir alcanzar un fin constitucionalmente legítimo, esto es, que la afectación al contenido de un derecho fundamental, principio o mandato de optimización debe perseguir una finalidad constitucionalmente válida.

A mayor desarrollo, ROGER ZAVALETA RODRIGUEZ ${ }^{55}$ indica que el fundamento del citado presupuesto radica en:" Que cualquier restricción o sacrificio de un derecho, principio o bien constitucional solo se justifica si, entre otros requisitos, se hace para la obtención de un bien valioso. En consecuencia, si dicho fin no existe o la medida restrictiva no es idónea o adecuada para obtenerlo, estamos frente a una lesión inútil y, por tanto, inconstitucional, pues carecería de justificación que se restrinja o limite un derecho, principio o bien constitucionalmente protegido sin que propenda a la realización de otro. Elprincipio de idoneidad, entonces, es una manifestación del óptimo de Pareto, el cual postula que debe privilegiarse el caso en que una posición se pueda mejorar sin ocasionar desventajas a otra".

Por su parte, el Tribunal Constitucional en la Sentencia recaída en el expediente $\mathrm{N}^{\circ}$ 00045-2004-AI, establece que el contenido del examen de idoneidad consiste en la relación de causalidad, de medio a fin. Posteriormente, en la Sentencia recaída en el proceso $\mathrm{N}^{\circ}$ 00034-2004-AI/TC, declaró que por el juicio de idoneidad toda injerencia en los derechos fundamentales debe ser apta o capaz para fomentar un objetivo constitucionalmente legítimo y supone la legitimidad constitucional del objetivo y la suficiencia de la medida utilizada.

Entonces, conjugando lo fundamentado por la doctrina y la jurisprudencia podemos establecer que el presupuesto de idoneidad, se configura con la verificación que la medida de limitación de un derecho fundamental, principio constitucional o mandato de optimización es idónea, por lo tanto, válida cuando se trata de obtener un fin

\footnotetext{
${ }^{55}$ Zavaleta Rodríguez 2014: 262.
} 
Journal homepage: http://revistas.unap.edu.pe/rd/ E-mail: revistaderecho@unap.edu.pe

constitucionalmente legítimo, conteniendo dos exigencia: en primer lugar, la identificación de un derecho, principio o mandato de optimización constitucionalmente relevante; $y$, en segundo lugar, que la medida adoptada sea un medio adecuado para lograr el fin de relevancia constitucional.

Para comprender mejor este presupuesto conviene citar un ejemplo de su aplicación, para lo cual nos remitimos a la Sentencia emitida por el Tribunal Constitucional en el expediente $\mathrm{N}^{\circ}$ 03901-2007-PA/TC (caso de la cadete del ejército expulsada) donde se resolvió por declarar inaplicable por inconstitucional la Resolución de la Comandancia General del Ejército que dispuso la separación definitiva de la demandante, en su condición de cadete de la Escuela Militar de Chorrillos, por la falta consistente en haber mantenido relaciones amorosas o sexuales con otro cadete, puesto que dicha falta estaba prevista en el artículo 69 del Reglamento de la Escuela Militar.

Al respecto, el Tribunal Constitucional consideró que la medida adoptada por la Comandancia General del Ejército restringía el derecho de la demandante al libre desarrollo de su personalidad, el cual garantiza la facultad de una persona de determinar con quien ha de mantener relaciones amorosas o sexuales. Tal restricción la evaluó como irrazonable e inconstitucional, bajo la consideración de que la medida no estaba justificada por ningún bien jurídico constitucional y no superaba el presupuesto de idoneidad. En ese sentido, el Tribunal Constitucional afirmó que no existía razón evidente ni argumento serio para sostener que la disciplina de la cadete podría resultar perjudicada si tienen aquel tipo de relaciones fuera de la Escuela Militar con otro cadete. No hay ninguna razón, ni lógica ni científica para aseverar que la obediencia a las reglas de la escuela, la obediencia a las jerarquías, el cumplimiento estricto de los deberes académicos, el profesionalismo académico y militar pueden resultar perjudicados o menguados si la cadete ha tenido este tipo de relaciones con otro cadete. El único argumento que parece subyacer a la prohibición comentada no parece ser sino un cierto prejuicio de hondas raíces subjetivas; sin embargo, la vulneración al derecho al libre desenvolvimiento de la personalidad no puede sustentarse en un simple prejuicio o subjetividad. Por ello, la medida restrictiva adoptada en el Reglamento de la entidad militar no es adecuada ni idónea para hacer valer la disciplina militar, por el contrario, afecta directamente el derecho constitucional líneas arriba descrito.

3.2.2.- Presupuesto de necesidad: Realizada la verificación de idoneidad de la medida, el siguiente paso es determinar si es necesaria, en el sentido de que no exista otra medida igualmente efectiva o adecuada para alcanzar el mismo fin, pero que implique una restricción menor para el derecho fundamental intervenido. En palabras más simples, el juicio de necesidad permite establecer si la medida restrictiva a un derecho, principio o mandato de optimización es realmente necesaria, esto es, si no existe una alternativa que sea menos gravosa o perjudicial para el derecho intervenido y que tenga igual o mayor adecuación con la finalidad perseguida.

Estando al significado del presupuesto de necesidad, URSULA INDACOCHEA PREVOST ${ }^{56}$ sostiene que: "El análisis comparativo estaría destinado a descartar que este medio

\footnotetext{
${ }^{56}$ Indacochea Prevost 2008: 53-66.
} 
Journal homepage: http://revistas.unap.edu.pe/rd/ E-mail: revistaderecho@unap.edu.pe

alternativo cumpla con dos condiciones, pues de llegar a verificar que ambas se cumplen conjuntamente, nos veríamos obligados a descartar la medida analizada, por inconstitucional. Así, estas condiciones se corresponden con dos fases consecutivas del análisis de la necesidad, y son las siguientes: i) Que alguno o algunos de los medios alternativos revista por lo menos la misma idoneidad que la medida interventora para alcanzar el objetivo de esta última; ii) Que dentro de los medios que resulten por lo menos igualmente idóneos, exista alguno que afecte el derecho fundamental intervenido, en una menor medida. Para realizar el análisis de necesidad es importante tener en cuenta que la idoneidad de la medida examinada y sus alternativas, debe apreciarse desde diversas perspectivas. Asi, desde el punto de vista de la eficacia, se debe verificar si alguno de los medios alternativos es tanto o más eficaz.para alcanzar el estado de las cosas que se persigue; desde la perspectiva de la temporalidad, si alguno puede contribuir a dicho propósito con igual o mayor rapidez; y finalmente desde el punto de vista de la probabilidad, si alguno de los medios alternativos lo hace con la misma o mayor seguridad que la medida interventora".

En esa misma lógica, el Tribunal Constitucional, en la sentencia recaída en el expediente $\mathrm{N}^{\circ}$ 00034-2004-AI/TC, comprender que para que opere la exigencia de necesidad no debe existir ningún otro medio alternativo que revista, por lo menos, la misma aptitud para alcanzar el objetivo propuesto y que sea más benigno con el derecho afectado. Se trata de una comparación de la medida adoptada con los medios alternativos disponibles, y en la cual se analiza, por un lado, la idoneidad equivalente o mayor del medio alternativo; y, por otro, su menor grado de intervención en el derecho fundamental.

El significado descrito se ve complementado con la sentencia recaída en el expediente $\mathrm{N}^{\circ}$ 045-2004-AI/TC, donde el Tribunal también está de acuerdo en establecer dos condiciones para que opere el presupuesto de necesidad; la primera, referente a la comparación de un medio alternativo igualmente idóneo, es decir, que alguno o algunos de los medios alternativos revista por lo menos la misma idoneidad que la medida interventora para alcanzar el objetivo de esta última; y, la segunda, que la evaluación de la intensidad de la intervención en el derecho fundamental afectado, es decir, que dentro de los medios que resulten por lo menos igualmente idóneos, exista alguno que afecte el derecho fundamental intervenido, en una menor medida.

En términos simples, para la aplicación de este requisito, el Juez debe analizar, si hay medios hipotéticos alternativos idóneos; para luego, verificar si tales medios idóneos no intervienen en la prohibición de discriminación, o, sí, interviniéndolo, tal intervención revista menor intensidad.

Para comprender mejor este requisito conviene citar como ejemplo, el análisis que hizo el Tribunal Constitucional en la Sentencia recaída en el expediente 00017-2008-AI, que trató la demanda de inconstitucionalidad interpuesta por cinco mil ciudadanos en contra de la Ley $\mathrm{N}^{\circ} 28564$ que prohibía crear filiales universitarias, con la justificación que con su creación no se venían cumpliendo con los niveles de calidad educativa que se necesita para dar una educación eficiente a los estudiantes universitarios. En dicha sentencia, el Tribunal estableció que la medida pasaba la exigencia de idoneidad porque la prohibición de crear filiales universitarias tenía por objetivo mejorar la calidad de la enseñanza universitaria; correspondiendo, determinar si existían otros medios que, siendo igualmente idóneos para cumplir con la finalidad de la norma, eran menos gravosos para los derechos de acceso a la educación universitaria, libre iniciativa privada y a la libertad de empresa que invocaban con vulnerados los demandantes. Al respecto, el Tribunal al 
Journal homepage: http://revistas.unap.edu.pe/rd/ E-mail: revistaderecho@unap.edu.pe

implementar el examen de necesidad estableció que existía un medio alternativo menos gravoso en relación a los derechos constitucionales afectados, el mismo que radicaba en adoptar medidas que permitan asegurar la creación de filiales que garanticen el ofrecimiento de un servicio educativo que cumpla con los niveles de calidad exigidos por el ordenamiento jurídico, sin necesidad de prohibirlas en absoluto, no se trataba de recurrir al facilismo de la prohibición sino más bien pasaba por implementar una política pública de mejoramiento de la enseñanza universitaria.

3.2.3.- Presupuesto de Proporcionalidad en sentido estricto: Por ésta exigencia se debe entender que la importancia del objetivo que persigue la intervención en el derecho fundamental debe estar en una relación adecuada con el significado del derecho intervenido, esto es, las ventajas que se obtengan mediante la intervención en el derecho fundamental debe compensar los sacrificios que ello implica para su titular y para la sociedad en general.

Estando al significado descrito, ROGER ZAVALETA RODRÍGUEZ ${ }^{57}$ agrega: "Luego que la medida en cuestión ha resistido los análisis de idoneidad y de necesidad, corresponde hacer una comparación entre la importancia de la intervención en el derecho fundamental y la importancia que tiene realizar el fin constitucional de la medida. Se trata de acreditar que existe un cierto equilibrio entre los beneficios que se obtienen con la medida restrictiva en orden a la protección de un bien constitucional o a la consecución de un fin legítimo y el perjuicio que dicha medida ocasiona respecto al ejercicio de un derecho o la satisfacción de otro bien o valor constitucional".

Por su parte, el Tribunal Constitucional en la sentencia recaída en el expediente $\mathrm{N}^{\circ}$ 0072-2004-AA/TC, argumenta que el juicio de proporcionalidad en sentido estricto busca establecer si la medida guarda una relación razonable con el fin que se pretende alcanzar, a través de un balance entre sus costos y sus beneficios. Luego, en la sentencia recaída en el expediente $\mathrm{N}^{\circ}$ 00030-2004-AI/TC, refiere que para analizar el presupuesto materia de comentario, se debe cumplir con tres criterios; el primero, referente a que la comparación entre medios y fines debe orientarse a determinar la intensidad de la limitación, para que cuanto mayor sea la limitación, más importantes deban ser los intereses generales que la regulación proteja; el segundo, responde a que cuanto mayor sea la importancia o jerarquía de los intereses perseguidos por la regulación, mejor podrán justificar una limitación en los derechos fundamentales; y, el tercero, busca establecer que cuanto más afecte una intervención a los derechos fundamentales, deban ser más cuidadosamente tenidas en cuenta las razones utilizadas para la justificación de la medida restrictiva.

En ese orden, ROGER ZAVALETA RODRIGUEZ"5 agrega, que: "El Tribunal Constitucional siguiendo a ROBERT ALEXY, ha incorporado una escala triádica, según la cual los grados de la intervención son los siguientes: grave, medio o leve, mientras que, en forma equivalente, los niveles o los grados de satisfacción de los derechos que juegan en sentido contrario son: elevado, medio o débil'. En tal sentido, se describe el cuadro con el contenido de escalas donde puede advertirse los resultados siguientes:

57 Zavaleta Rodríguez 2014: 276-277.

${ }^{58}$ Zavaleta Rodríguez 2014: 286. 
Journal homepage: http://revistas.unap.edu.pe/rd/ E-mail: revistaderecho@unap.edu.pe

\begin{tabular}{|r|c|c|c|}
\hline CASO & INTERVENCIÓN & SATISFACCIÓN & RESULTADO \\
\hline & Leve & Elevada & Constitucional \\
C1 & & & \\
\hline C2 & Leve & Media & Constitucional \\
\hline C3 & Leve & Débil & Empate \\
\hline C4 & Media & Elevada & Constitucional \\
\hline C5 & Media & Media & Empate \\
\hline C6 & Media & Débil & Inconstitucional \\
\hline C7 & Grave & Elevada & Empate \\
\hline C8 & Grave & Media & Inconstitucional \\
\hline C9 & Grave & Débil & Inconstitucional \\
\hline
\end{tabular}

Interpretando el cuadro de aplicación en la ponderación, tenemos que en los casos C1; C2; y C4, cuando la intervención de la medida es leve o media y la satisfacción del derecho constitucional que prevalece es medio o elevado tendremos un resultado constitucional; por el contrario, en los casos C6; C8 y C9, cuando la intervención de la medida es media o grave y la satisfacción del derecho afectado débil o media, tendremos un resultado constitucional; y, por último, en los casos de empate (C3; C5 y C7), no basta la ponderación, se necesitará de una carga argumentativa adicional para solucionar el conflicto.

Entonces, la exigencia de proporcionalidad en sentido estricto, implica que el contenido del derecho fundamental afectado debe ser proporcional en comparación con la finalidad que esta persigue, guardando con ella una relación de equilibrio razonable, tal cual aparece en el cuadro de escalas de ponderación arriba descrito.

Ahora bien, en referencia al equilibrio razonable, URSULA INDACOCHEA PREVOST" sostiene que: "Se obtiene al ponderar, es decir, sopesar, comparar, por un lado los perjuicios que la medida interventora supone para el ejercicio del derecho fundamental afectado, y por otro, los beneficios que se derivan de ella, para la satisfacción del otro principio que constituye su finalidad. Asi, una medida podrá ser calificada como proporcionada, cuando las ventajas que se obtienen de su adopción es mayor, compensándolos con los sacrificios que esta implica para los titulares del bien constitucional afectado".

En esa lógica, la adopción de una medida que implique un alto grado de sacrificio o limitación a un derecho fundamental, sería desproporcionada si de ella se derivase apenas un pequeño beneficio para el principio constitucional perseguido. Por el contrario, será proporcionada una medida cuya adopción va a generar un gran beneficio para la satisfacción de un bien constitucional, y que únicamente implicará un mínimo sacrifico para quien resultará afectado.

En conclusión, el principio de proporcionalidad en sentido estricto exige valorar si los beneficios que se derivan de la consecución de dicho bien colectivo son mayores que los perjuicios inherentes al sacrificio del derecho fundamental. La proporcionalidad en

\footnotetext{
${ }^{59}$ Indacochea Prevost 2008: 27-38.
} 
Journal homepage: http://revistas.unap.edu.pe/rd/ E-mail: revistaderecho@unap.edu.pe

sentido estricto es propiamente lo que se conoce como la ponderación entre los principios en colisión.

Para comprender mejor este presupuesto, conviene citar un ejemplo proveniente de la aplicación del presupuesto que ha hecho el Tribunal Constitucional en la sentencia recaída en el expediente $\mathrm{N}^{\circ}$ 02132-2008-AA, sobre la materia de amparo, por la cual la demandante pretendía que se declararan nulas las resoluciones de primera y segunda instancia en virtud de las cuales se había declarado prescrita la ejecución de una sentencia sobre pensión de alimentos, emitida a favor de su menor hijo. Dichas resoluciones se fundamentaron en el artículo 2001 inciso 4) del Código Civil, que establece el plazo de prescripción de dos años respecto de la acción que proviene de una pensión alimenticia. La demanda en cuestión al ser resuelta por el Tribunal Constitucional mediante la utilización del Test de Proporcionalidad estableció que la norma que establecía un plazo de prescripción para ejecutar una sentencia en materia de alimentos pasaba el examen de idoneidad porque era una medida adecuada para eliminar cualquier tipo de indefinición en cuanto al tiempo durante el cual procedía ejecutar una sentencia; sin embargo, no cumplía con pasar el examen de necesidad porque resulta inexplicable que el Código Civil en su artículo 2001 fija la prescripción de la acción que nace de una ejecutoria en un plazo de 10 años cuando se trata de cualquier tipo de deuda, sin embargo, cuando se trata de alimentos se reduce sólo a 02 años, estando por medio el principio de interés superior del niño y adolescente, consecuentemente, es una medida en exceso restrictiva existiendo otras alternativas. Finalmente, el Tribunal -pese a que no existía la obligación por no haberse superado el juicio de necesidad- se pronunció si el caso cumplía con la exigencia de proporcionalidad en sentido estricto, estableciendo que es grave la intensidad de la intervención en el derecho a la efectividad de las resoluciones judiciales y el derecho de los niños y adolescentes a percibir alimentos, mientras el grado de optimización o realización del fin constitucional (seguridad jurídica) es elevado. Por ello, a criterio del Tribunal Constitucional aplicando la ponderación en sentido estricto aparentemente estamos frente a un empate entre los derechos en conflictos, pero que estando a la naturaleza del caso, en el que se encuentran involucrados los derechos de alimentos de un menor, debe prevalecer el principio de protección del interés superior del menor sobre el principio de seguridad jurídica contenido en el artículo 2001 inciso 4) del C.C.

Finalmente y luego de haber desarrollado el contenido de cada uno de los presupuestos que dan vida al Test de Proporcionalidad se logra establecer que toda intervención en los derechos fundamentales que no observe las exigencias de estos requisitos es ilegítima y, por lo tanto, debe ser declarada inconstitucional. 
Journal homepage: http://revistas.unap.edu.pe/rd/ E-mail: revistaderecho@unap.edu.pe

\section{4.- APLICACIÓN DEL TEST DE PROPORCIONALIDAD EN LA ARGUMENTACIÓN DE LAS RESOLUCIONES JUDICIALES EN MATERIA CIVIL.}

\section{1.- Aplicación del Test de Proporcionalidad en proceso de alimentos.}

A través de la sentencia $N^{\circ}$ 50-2017-FC, emitida por el Tercer Juzgado de Paz Letrado de Puno en el Expediente 1345-2016-0-2101-JP-FC-03, sobre la materia de alimentos, la demandante en representación de sus tres menores hijos solicitó al demandado (quien se desempeñaba como fiscal titular del Ministerio Público), cumpla con acudir con una pensión alimenticia del 60\% del total de sus ingresos a razón del $20 \%$ para cada uno los menores, incluyendo remuneraciones, gratificaciones, bonificaciones, bonos de productividad, bono fiscal, gastos operativos y cualquier otro beneficio que perciba por el puesto laboral que desempeña. El demandado al absolver el traslado de la demanda sustentó su defensa que en mérito al Decreto de Urgencia $N^{\circ}$ 114-2001, el monto dinerario que recibe por concepto de gastos operativos no tiene naturaleza remuneratoria ni son computables para efectos pensionarios, así como tampoco sirven de base de cálculo para ningún beneficio deviniendo en nula cualquier disposición en contrario, por consiguiente, no podían ser comprendidos para el pago de la obligación alimentaria, debiendo tomarse en cuenta únicamente su sueldo mensual y el bono de asignación fiscal, conceptos que en la práctica ascienden a un monto aproximado de S/. 2,550.00 soles (cantidad que con el pago de gastos operativos se incrementa a un total de S/. 13,500.00 soles). Después de llevada a cabo la Audiencia Única, el juez emitió la Sentencia No 50 2017-FC, declarando fundada en parte la demanda fijando la pensión alimenticia en un monto fijo de S/. 1,300.00 soles por cada menor, excluyendo el pago en porcentaje solicitado en la demanda, en virtud de que por la vigencia del Decreto de Urgencia $\mathrm{N}^{\circ}$ 114-2001, los llamados gastos operativos no tienen naturaleza remuneratoria, por lo que no son computables para el pago de la prestación alimentaria. No obstante lo anotado, el juez refiere que estando a la Declaración Jurada Anual de Ingresos del demandado presentada como prueba extraordinaria por la demandante, donde se consigna él emplazado tiene por haber mensual la suma de S/. 13,500.00 soles, sumado al hecho de que en la etapa conciliatoria de la Audiencia Única, ofreció abonar un total de S/. 3,500.00 en favor de sus tres hijos, se formó la convicción de que éste tiene una mayor disponibilidad económica de lo que indica percibir como sueldo y bono fiscal, por ello, resolvió por cambiar del monto porcentual de descuento solicitado en la demanda por una cantidad fija para cada menor, ordenando que el demandado haga de forma directa el depósito dinerario, por consiguiente, el descuento no se efectuaría por planilla. Finalmente, el juez deja constancia que ha resuelto el caso cumpliendo con los criterios de razonabilidad y proporcionalidad.

En el caso descrito, la demandante sustentó su pretensión alimentaria en el principio de interés superior del niño y adolescente, así como también el derecho constitucional a los alimentos, que en mérito a lo regulado en el artículo 4 y 6 de la Constitución del Estado adquieren la calidad de derechos fundamentales, por ser una política del Estado proteger a la infancia del país, se funda en la dignidad misma del ser humano, en las características propias de los niños, y en la necesidad de propiciar el desarrollo de estos, con pleno aprovechamiento de sus potencialidades. A mayor detalle, el derecho a los alimentos se 
Journal homepage: http://revistas.unap.edu.pe/rd/ E-mail: revistaderecho@unap.edu.pe

considera como un derecho fundamental del ser humano, está garantizado por valores como son la unidad, la solidaridad y la asistencia, siendo que en el ámbito del derecho civil se traducen a la vez, como un derecho y como una obligación. Como un derecho de quien debe percibirlos por carecer de posibilidades para subsistir y como una obligación del deudor alimentario, el cual está sujeto por ley a ejecutar una prestación.

En contraposición, la parte demandada sustenta su defensa en el mandato legal contenido en el Decreto de Urgencia $N^{\circ}$ 114-2001, el mismo que el Tribunal Constitucional en la sentencia recaída en el expediente $\mathrm{N}^{\circ} 1875-2004-\mathrm{AA} / \mathrm{TC}$, señalo que su finalidad es coadyuvar al proceso de renovación en el sistema judicial y generar un clima de respeto a la legalidad y seguridad jurídicas, con el propósito de preservar los derechos ciudadanos y, al mismo tiempo, atraer inversiones nacionales y extranjeras para cuyo efecto es menester adoptar medidas destinadas a reinstitucionalizar el sistema de justicia, siendo dichos objetivos de interés nacional y requieren medidas económicofinancieras extraordinarias de carácter urgente, razón por lo cual es de estricta justicia proporcionar a los magistrados y fiscales recursos que les permitan contar con ingresos adicionales para que sean aplicados a cubrir los gastos correspondientes al desempeño de sus funciones; habida cuenta de que sus ingresos no guardan relación con sus elevadas responsabilidades y no reflejan el hecho de estar impedidos, por prohibición constitucional, de desempeñar cualquier otra actividad pública o privada, y que dicha circunstancia se ve agravada por el sistema de trabajo, que determina que los magistrados y fiscales no dispongan de una infraestructura mínima para el desempeño de sus tareas, enmarcándose el citado el Decreto de Urgencia dentro del principio de seguridad jurídica que se encuentra implícitamente reconocido en el artículo 3 de la Constitución del Estado.

Entonces, tenemos que en el caso propuesto existe una colisión entre el principio interés superior del niño y el derecho de alimentos del cual goza todo menor por el hecho de serlo con el principio de seguridad jurídica proveniente del Decreto de Urgencia $\mathrm{N}^{\circ}$ 114-2001, correspondiendo recurrir a los requisitos del Test de Proporcionalidad a efecto de dilucidar y establecer cuál principio debe prevalecer ante el supuesto de hecho descrito, para lo cual se requiere implementar el Test de Proporcional en mérito al análisis de sus presupuestos, así tenemos que:

a) Respecto al presupuesto de idoneidad; juicio que se configura en virtud a que toda intervención en los derechos fundamentales debe ser idónea para contribuir alcanzar su fin constitucional, por lo que la afectación al contenido de un derecho fundamental, principio o mandato de optimización debe perseguir una finalidad constitucionalmente válida.

Aplicando el presupuesto descrito al caso concreto se observa que el Estado al momento de buscar reinstitucionalizar el sistema justicia a través del llamado pago por gastos operativos a favor de jueces y fiscales, que en la práctica es una entrega de dinero no reembolsable que va en favor de sus ingresos, ha creado una legislación no acorde con la política laboral y fiscal del Estado, por ello es que cuando se requiere que los verdaderos ingresos de dichos funcionarios públicos sean tomados en cuenta para el cumplimiento de una obligación alimentaria, el juez se limite a indicar que los gastos operativos por regulación de una ley especial, no tienen efectos remuneratorios, por lo que no son computables para la prestación alimentaria, siendo 
Journal homepage: http://revistas.unap.edu.pe/rd/ E-mail: revistaderecho@unap.edu.pe

que dicha medida se enmarca dentro del principio de seguridad Jurídica e incluso dentro del principio de independencia judicial; sin embargo, el ejecutivo que dictó dicha ley no ha previsto que esa medida legislativa no es idónea para lograr la vigencia de otro Principio Constitucional que es el referente al Interés superior de los niños y adolescentes, así como también el derecho fundamental que estos tienen a que se le provea de alimentos por parte de sus progenitores, en consecuencia, la medida restrictiva contenida en el Decreto de Urgencia $\mathrm{N}^{\circ} 114-2001$, no supera el juicio de idoneidad, razón por la cual deviene en inconstitucional para el caso materia de análisis.

b) Respecto al presupuesto de necesidad; juicio por el cual se establece si la medida restrictiva a un derecho, principio o mandato de optimización es realmente necesaria, esto es, si no existe una alternativa que sea menos gravosa o perjudicial para el derecho intervenido y que tenga igual o mayor adecuación con la finalidad perseguida.

En el caso propuesto tenemos que el Decreto de Urgencia $\mathrm{N}^{\circ} 114-2001$, fue emitido para coadyuvar al proceso de renovación en el sistema judicial y generar un clima de respeto a la legalidad y seguridad jurídicas, con el propósito de preservar los derechos ciudadanos y, al mismo tiempo, atraer inversiones nacionales y extranjeras, efectivizando la reinstitucionalización del sistema de justicia; lo cual es importante para el desarrollo de la Justicia en nuestro país; sin embargo, el ejecutivo estuvo en la posibilidad de emitir otro tipo de dispositivo que le permita lograr el objetivo propuesto su afectar el principio de interés superior del niño y adolescente, así como el derecho fundamental a los alimentos, así por ejemplo, bien pudo implementar una reforma en la política de remuneraciones de los jueces y fiscales, por el cual se elimine los llamados "gastos operativos" para que sean parte de la remuneración, lo cual evitaría afectaciones a derechos vinculados al deber alimentario, que por su naturaleza son de primer orden en la escala de derechos fundamentales, lográndose de este modo que el deudor alimentario por más fiscal que sea responda a su obligación en base a su totalidad de ingresos económicos. Por todo ello, queda claro que la regulación normativa contenida en el Decreto de Urgencia $\mathrm{N}^{\circ} 114-2001$, no supera el juicio de necesidad.

c) Respecto al presupuesto de ponderación en sentido estricto; juicio que implica que la intervención en el derecho fundamental debe estar en una relación adecuada con el significado del derecho intervenido, esto es, las ventajas que se obtengan mediante la intervención en el derecho fundamental debe compensar los sacrificios que ello implica para su titular y para la sociedad en general.

Aplicándolo al caso propuesto se tiene que el contenido del Decreto de Urgencia $\mathrm{N}^{\circ}$ 114-2001, por el cual se busca reinstitucionalizar el sistema de Justicia otorgando un mayor ingreso a los Jueces y Fiscales por el trabajo que realizan, no guarda correspondencia o equilibrio con el Principio de Interés Superior del Niño y el Derecho de Alimentos, pues la intervención a ese derecho es muy grave con la medida legal dictada por el ejecutivo, pues no existe correlación en que un fiscal que en la práctica recibe una remuneración mensual de $\mathrm{S} / .13,500.00$ soles, pretenda otorgar a sus hijos por concepto de alimentos la suma de S/.1,300.00, soles, es 
Journal homepage: http://revistas.unap.edu.pe/rd/ E-mail: revistaderecho@unap.edu.pe

desproporcional desde cualquier ángulo legal, razón por la cual tampoco se supera el juicio de proporcionalidad en sentido estricto.

De lo desarrollado se debe concluir que el Test de Proporcionalidad como pauta metodológica puede ser aplicado para justificar la argumentación de sentencias en materia del Derecho Civil, específicamente, para las pretensiones de alimentos, lográndose con ello una prevalencia de los Principios que los inspiran sobre normas legales que se enmarcan dentro del principio de seguridad.

\section{3.- Aplicación del Test de Proporcionalidad en proceso de ineficacia de acto jurídico.}

La Sala Civil Permanente de la Corte Suprema mediante la Casación No 3693-2010 _ CUSCO, declaró fundado el Recurso de Casación presentado por el demandante, respecto a la pretensión de nulidad del acto jurídico contenido en una escritura pública transferencia de un bien inmueble por las causales de finalidad ilícita y simulación absoluta al amparo del artículo $219^{\circ}$ del Código Civil y el artículo $97^{\circ}$ del Código Penal, que regula la nulidad de los actos de disposición del condenado que disminuya su patrimonio con miras a incumplir el pago de reparación civil, precisando, que el demandado había cometido en agravio del actor un acto ilícito, específicamente, había hurtado un vehículo de su propiedad, razón por la cual fue llevado a juicio penal encontrándosele responsable, consecuentemente, obligado a cumplir una pena y al pago de la reparación civil, sin embargo, para evadir dicha obligación pecuniaria había celebrado una compraventa simulada de uno de los inmuebles de su propiedad con un tercero, dando origen a la interposición de la demanda de nulidad, la misma que en primera instancia fue declarada fundada, interponiéndose recurso de apelación por parte del demandado, que fue resuelto por la Sala Civil del Cusco, declarando improcedente la demanda por falta de conexidad lógica entre el petitorio y la demanda, pues a su criterio correspondía interponer una demanda de ineficacia de acto jurídico y no de nulidad, teniendo en cuenta la disquisición doctrinaria sobre la diferencia entre los conceptos de invalidez (nulidad e ineficacia), para concluir que ese tipo de contratos son válidos pero ineficaces, dando lugar, a la emisión de una sentencia inhibitoria, es decir, aquella que por deficiencia en la relación procesal ya sea por el incumplimiento de los presupuestos procesales y las condiciones de la acción, impiden un pronunciamiento de fondo.

Al respecto, al Corte Suprema consideró que la Sala Civil de Cusco estaba en la obligación de recurrir al Principio Iura Novit Curia, por el cual se faculta a los jueces aplicar el derecho pertinente aun cuando no éste no haya sido alegado por las partes o lo haya sido de modo o forma equivocada, añadiendo, que la Sala Civil no realizó un debido juicio de proporcionalidad, ya que, había afectado el acceso a la tutela jurisdiccional efectiva y el debido proceso al tomar la decisión de declarar improcedente la demanda.

Como se ha desarrollado, el derecho a la tutela jurisdiccional efectiva se configura, fundamentalmente, como la garantía de que las pretensiones de las partes que intervienen en un proceso serán resueltas por los órganos judiciales con criterios razonables y tiene como contenido básico el de obtener una respuesta motivada a las pretensiones planteadas. Este derecho tiene reconocimiento constitucional pues se encuentra recogido en el artículo 139 numeral 3) de la Constitución del Estado. 
Journal homepage: http://revistas.unap.edu.pe/rd/ E-mail: revistaderecho@unap.edu.pe

Por su parte, el principio Iura Novit Curia, es el aforismo que se utiliza para dejar establecido que el juuez es quien conoce el derecho, debiendo las partes limitarse a explicar los hechos, siendo que este principio forma parte del deber de motivación que tienen los jueces y siendo que también constituye un derecho constitucional, pues se encuentra consagrado en el artículo 139 inciso 5) de la Constitución del Estado.

En contraposición, se encuentra la facultad que otorga a los jueces el ordenamiento procesal civil para emitir una decisión inhibitoria, cuando adviertan al momento de resolver una causa el incumplimiento de los presupuestos procesales y las condiciones de la acción, es decir, cuando detecten la imposibilidad de pronunciarse sobre el fondo de un asunto por aspectos formales, esto es, una sentencia que no resuelve el fondo del asunto materia de controversia, así lo regula el artículo 121 del Código Procesal Penal en su último párrafo. El legislador justifica la existencia de esa disposición en el principio de seguridad jurídica que debe otorgar la ley, pues la misma es una garantía que informa a todo el ordenamiento jurídico y consolida la interdicción de la arbitrariedad.

En el caso descrito se percibe una contraposición entre ambos principios, por lo que corresponde aplicar el Test de Proporcionalidad para establecer cuál de ellos debe prevalecer para lograr el fin constitucionalmente legítimo que éste acorde con el valor justicia, así tenemos que:

a) Respecto al presupuesto de Idoneidad; Como se ha desarrollado este presupuesto implica que toda medida debe ser adecuada o idónea para fomentar la obtención de un fin constitucionalmente legítimo.

Aplicando el concepto descrito al supuesto que nos ocupa se debe observar que la facultad que tienen los Jueces para advertir al momento de emitir sentencia la falta de un presupuesto de la relación procesal y en mérito a esto declarar la improcedencia de la demanda es válida para proteger la seguridad jurídica, empero, no es idónea para alcanzar el derecho que tiene toda parte que interviene en un litigio para obtener una respuesta del órgano jurisdiccional sobre el problema que lo motiva a recurrir a él, independientemente que se le dé o no la razón, pues es incomprensible que después de años invertidos en la tramitación de un proceso, de gastos en tasas y derechos judiciales, así como el pago de los honorarios de los abogados, de tiempo y esfuerzo para seguir la tramitación del proceso, se obtenga como respuesta del juzgador un fallo inhibitorio que en buena cuenta nos indica que por deficiencias procedimentales, el Juez se abstiene de emitir su veredicto, razón por la cual la medida interventora respecto al derecho limitado no supera el juicio de adecuación o idoneidad.

b) Respecto al presupuesto de Necesidad; por el cual corresponde identificar si no había una alternativa que fuera menos gravosa o perjudicial para el derecho intervenido y que tenga igual o mayor adecuación con la finalidad perseguida.

Ahora bien, en relación a los supuestos de hecho que conforman el caso descrito, se observa que tampoco supera el juicio de necesidad porque la decisión de la Sala Civil de Cusco de emitir un pronunciamiento inhibitorio porque la pretensión del demandante no conjuga con la teoría del derecho civil sobre la nulidad e ineficacia del acto jurídico es en exceso rigurosa, tanto más, si pudieron apelar al Principio Iura Novit Curia, para reconducir la pretensión del demandante 
Journal homepage: http://revistas.unap.edu.pe/rd/ E-mail: revistaderecho@unap.edu.pe

de nulidad hacía la ineficacia, tanto más, si el efecto jurídico de ambas instituciones es el mismo, alternativa que les hubiese permitido a su vez hacer valer el derecho a la tutela jurisdiccional efectiva, pues se lograría emitir una resolución razonable y racional, teniendo en cuenta el actuar del demandado de disponer simuladamente bienes de su propiedad para no pagar el concepto de la reparación civil por un acto ilegal que cometió en contra del demandante.

c) Respecto al presupuesto de Proporcionalidad en Sentido Estricto; por el cual corresponde hacer una comparación entre la importancia de la intervención en el derecho fundamental y la importancia que tiene realizar el fin constitucional de la medida.

Aplicando dicho concepto al caso, tampoco se advierte que se supera dicho presupuesto pues no puede haber equilibrio constitucional ante una intervención grave que supone un pronunciamiento inhibitorio por una disquisición teórica que produce una satisfacción débil, por no decir nula, del derecho a la tutela jurisdiccional efectiva.

Finalmente, se debe señalar que si bien es cierto que la Corte Suprema apelando a la aplicación de los principios Procesales referentes a la tutela jurisdiccional efectiva y Iura Novit Curia, concluye en declarar fundada la Casación en mención, también es verdad que lo correcto era aplicar el Test de Proporcionalidad, tanto más, si al concluir su fundamentación refieren que fallaban en el sentido descrito utilizando los criterios de proporcionalidad y razonabilidad.

\section{CONCLUSIONES}

> Cuando el Juez deba cumplir con justificar su decisión sobre determinado conflicto de intereses o incertidumbre jurídica debe recurrir en primer término a los principios y derechos consagrados en la Constitución de Estado, esto es, debe comenzar su análisis del caso bajo una óptica de control constitucional, para lo cual debe recurrir a los métodos de interpretación y argumentación, siendo de mucha utilidad recurrir a la ponderación que se materializa a través del test de proporcionalidad, para lograr la vigencia de los derechos fundamentales y los principios o mandatos de optimización.

$>$ La ponderación sirve para resolver la incompatibilidad entre los principios o mandatos de optimización que rigen un determinado ordenamiento jurídico, en especial, de aquellos que tienen relevancia constitucional, contribuyendo a independencia funcional del Juez, quien encuentra en su utilización una herramienta que le permitirá motivar adecuadamente su decisión y en mérito a ello actuar con imparcialidad al momento de resolver las controversias jurídicas sometidas a su conocimiento, incluso, controlar las potenciales injerencias de los otros poderes estaduales y a la vez constituirse en el principal garante de los derechos de los ciudadanos.

$>$ La ponderación encuentra en el llamado Test de Proporcionalidad, el instrumento metodológico para su aplicación al caso concreto, garantizando al individuo mediante la adecuación, necesidad y proporcionalidad en sentido estricto, la prevalencia de sus derechos fundamentales. 
Journal homepage: http://revistas.unap.edu.pe/rd/ E-mail: revistaderecho@unap.edu.pe

$>$ El Test de Proporcionalidad es un instrumento metodológico con reconocimiento constitucional que permite establecer cuando un derecho fundamental debe ser intervenido para preservar otro de mayor valor ante un supuesto de hecho concreto.

$>$ Estando a los casos prácticos vinculados al Derecho Civil y que han sido desarrollados en el trabajo de investigación, se ha logrado establecer el Test de Proporcionalidad, puede ser aplicado por parte de los Jueces especializados en esa materia, con la finalidad de hacer prevalecer la vigencia de los derechos fundamentales, los bienes constitucionales y los principios o mandatos de optimización contenidos en la Constitución frente a la enmarañada y contradictoria legislación normativa que erróneamente los induce a realizar una aplicación formalista de la ley.

\section{BIBLIOGRAFIA}

ALEXY, Robert. 1993. Teoría de los Derechos Fundamentales. Madrid: Centro de Estudios Constitucionales.

BERNAL PULIDO, Carlos. 2005. El derecho de los derechos. Lima: Editorial Cordillera S.A.C.

CARNELUTTI, Francesco. 1994. Sistema de Derecho Procesal Civil. Buenos Aires: Ed. UTEMA. II Tomo.

CORREA HENAO, Magdalena. 2003. La limitación de los Derechos Fundamentales. Bogotá: Instituto de Estudios Constitucionales Carlos Restrepo Piedrahita.

CASTILlO ALVA, José Luis; LUJÁN TÚPEZ, Manuel y ZAVALETA RODRIGUEZ, Roger. 2004. Razonamiento Judicial, interpretación, argumentación y motivación de las resoluciones judiciales.1 ra Edición. Lima: Gaceta Jurídica.

CASTILlO CÓRDOVA, Luis. 2008. Hacía una Reformulación del Principio de Proporcionalidad, pp. 37-52. En: Gaceta Constitucional, Lima, N$^{\circ} 08$.

CHAMORRO BERNAL, Francisco. 1994. La tutela judicial efectiva, Barcelona: Bosch.

DE DOMINGO PÉREZ, Tomás. 2008. Neoconstitucionalismo, justicia y principio de proporcionalidad, pp. 17-32. En: Gaceta Constitucional, Lima, $N^{\circ} 8$.

GONZÁLEZ ALVAREZ, Roberto. 2013. Neoprocesalismo - Teoría del Proceso Civil Eficaz. Lima: ARA editores.

GONZALES PÉREZ, Jesús. 2001. El derecho a la tutela jurisdiccional efectiva, 3ra. Edición. Madrid: Civitas.

INDACOCHEA PREVOST, Úrsula. 2008. Fundamento, estatus jurídico, caracteres y exigencias del principio de proporcionalidad, pp. 53-66. En: Gaceta Constitucional, Lima, $\mathrm{N}^{\circ} 8$.

INDACOCHEA PREVOST, Úrsula. 2008. El principio de proporcionalidad como criterio metodológico para evaluar las limitaciones al contenido de los derechos fundamentales, pp. 27- 38. En: Gaceta Constitucional, Lima, $\mathrm{N}^{\circ} 2$.

MALPARTIDA CASTILLO, Víctor. 2008. Casación, debido proceso, derecho a la tutela jurisdiccional efectiva y motivación aparente, pp. 95-106. En Jus Jurisprudencia, Lima, $\mathrm{N}^{\circ} 01$. 
Journal homepage: http://revistas.unap.edu.pe/rd/ E-mail: revistaderecho@unap.edu.pe

PEYRANO, Jorge. 1995. El derecho a obtener el dictado de la sentencia de mérito. Derecho Procesal Civil. Lima: Ediciones Jurídicas.

PRIORI POSADA, Giovanni. 2003. La efectiva tutela jurisdiccional de las situaciones materiales: hacia una necesaria reivindicación de los fines del proceso, pp. 273 - 292. En: Revista Ius et veritas, Lima. N²6.

RUBIO CORREA, Marcial. 2009. El Sistema Jurídico Introducción Al Derecho, Décima Edición. Lima: PUCP.

ZAVALETA RODRIGUEZ, Roger. 2014. La motivación de las resoluciones judiciales como argumentación jurídica. Lima: Editorial Grijley.

ZEGARRA ESCALANTE, Hilmer. 2010. Motivación de las Resoluciones, pp. 8791. En: Actualidad Jurídica, Lima, N²01. 